\title{
Correction to: Staged testing as a solution to the challenges of testing lower risk patients
}

\author{
Venkatesh L. Murthy, MD, PhD, FASNC, and Khurram Nasir, MD, MPH, MSc ${ }^{b}$ \\ a Division of Cardiovascular Medicine, Department of Internal Medicine, University of Michigan, \\ Ann Arbor, MI \\ b Division of Cardiovascular Medicine, Center for Outcomes \& Research Evaluation (CORE), Yale \\ University School of Medicine \& Yale New Haven Health, New Haven, CT
}

doi: 10.1007/s12350-019-01592-4

\section{CORRECTION TO: \\ JOURNAL OF NUCLEAR CARDIOLOGY \\ HTTPS://DOI.ORG/10.1007/S1 2350-018-1437-Y}

The family name of the second author was originally published with an extra "s". "Nassir" should be "Nasir". The original article has been corrected.

The original article can be found online at https://doi.org/10.1007/ s12350-018-1437-y.

Reprint requests: Venkatesh L. Murthy, MD, PhD, FASNC, Division of Cardiovascular Medicine, Department of Internal Medicine, University of Michigan, 1500 E. Medical Center Dr, SPC 5873, Ann Arbor, MI 48109-5873; vlmurthy@med.umich.edu

J Nucl Cardiol 2020;27:1379.

$1071-3581 / \$ 34.00$

Copyright (c) 2019 American Society of Nuclear Cardiology. 